\title{
Public and private measures of consumer confidence in Turkey:
}

\section{Substitutes or complements}

\author{
Erhan Aslanoğlu ${ }^{1}$, Plnar Deniz ${ }^{2}$ \\ (1. Economics Department, Marmara University, Goztepe 34722, Turkey; \\ 2. European Union Institute, Marmara University, Goztepe 34722, Turkey)
}

\begin{abstract}
Consumer confidence indices are among the major economic variables as private consumption stands as the major component of aggregate demand in many economies. This is also relevant for an emerging economy like Turkey. "What determines consumer confidence?" is one of the most popular questions in the literature of consumer surveys. There are two consumer confidence indices regularly released in Turkey. One is released by a private corporation, CNBC-e, in the first day of every month since January 2002. The other one is released by two public institutions, Central Bank of the Republic of Turkey (CBRT) and Turkish Statistical Institute (TURKSTAT), jointly since 2004. Although the goal is the same for both indices, there are differences between them in terms of the methodology and sampling size. This study has two aims: One is to detect the degree of correlation between these indices which will allow for commenting on the reliability of the indices; The other one is to test the relation between Gross Domestic Product (GDP), unemployment rate variables and the consumer confidence in Turkey by using both indices.
\end{abstract}

Key words: consumer confidence index; correlation; cointegration

\section{Introduction}

In Turkey, two consumer confidence indices are carried out: TURKSTAT Consumer Confidence Index ${ }^{1}$ (CCI) and CNBC- $e^{2}$ CCI. In this sense, it is crucial to check whether the two indices are consistent with each other. In order to test the consistency of the indices, first of all, the correlation between them is checked. Secondly, one by one, the relationships between CCI and the macroeconomic variables, namely, as GDP and unemployment rate, that are highly expected to have an impact on CCI, are analyzed. Moreover, a dummy variable is employed in order to take into account of the global crisis period.

What determines consumer confidence in Turkey has so far been analyzed (Çelik \& Aslanoğlu, 2006; Çelik \& Aslanoğlu, 2008). These studies have basically focused on the relationship among financial sector variables and consumer confidence. Foreign exchange rates, interest rates and stock market exchange have been found to be affecting consumer confidence in Turkey. For the real side of the economy, industrial output has been found to be correlated with the consumer confidence. Apart from these factors, previous studies on other countries suggest that unemployment rate or employment opportunities are expected to affect consumer confidence. One of the

Erhan Aslanoğlu, Ph.D., associate professor of economics, Economics Department, Marmara University; research field: macroeconomics.

Pınar Deniz, Ph.D. candidate, European Union Institute, Marmara University; research field: economic growth.

1 TURKSTAT CCI is carried out in collaboration with Central Bank of the Republic of Turkey and Turkish Statistical Institute.

${ }^{2}$ CNBC-e CCI is carried out by a private institution. 
major aims of this paper is to test the relationship between unemployment and consumer confidence in Turkey using the consumer confidence indices in Turkey. It is expected to contribute to the understanding of consumer behavior and growth dynamics in Turkey.

In the second section of the study, the literature that investigates the relationship between consumer confidence indices and some macroeconomic variables will be summarized. Detailed characteristics of each consumer confidence index and relevant methodology and empirical findings are covered in the third section. Last section concludes the paper.

\section{Literature}

Although there is no consensus on the issue, the literature generally suggests that the consumer sentiments are affected by some macroeconomic variables such as income, inflation and/or unemployment rate. Adams and Green (1965) discuss the high impact of unemployment rate and employment conditions and relatively lower impact of income on consumer sentiments. Alternatively, Juster and Wachtel (1972) suggest the significancy of unanticipated inflation and real income changes in explaining consumer sentiment. Lovell (1975) observes that consumer sentiment index is negatively affected by economic discomfort index which consists of a summation of inflation and unemployment. In a similar manner, Oest and Franses (2008) reveal that some macroeconomic data have strong effect on confidence, employing the US and the Netherlands data. While inflation and unemployment rates are observed to have negative impact, increase in disposable income and stock exchange have positive impact on confidence. Mentioning about liquidity hypothesis theory of Mishkin (1978), Throop (1992) employs US data and display that consumer sentiment is significantly affected by transitory income, change in the unemployment rate and some other variables.

On the other hand, many studies give emphasis on the forecasting power of sentiment indices on macroeconomic trends of the economies. With the pioneers of Acemoglu and Scott (1994) and Carroll, et al (1994), the studies result in having attention on consumer confidence indices since the predictive power of the indices are generally detected via several analysis. Some of the related empirical papers are as follows: Matsusaka and Sbordone (1995) employ US quarterly data within the period 1953-1988 to analyze the relationship between consumer sentiment and GNP. Using Granger causality, they find that there is causality from consumer sentiment to GNP. Utaka (2003), employing vector autoregression, analyzes consumer confidence as a factor in explaining the economy using quarterly Japan data. He finds that confidence only has an effect on short-term economic fluctuations, however, no effect is detected in the long run. Afshar and Zomorrodian (2007), using quarterly data for the U.S. from 1980 to 2005, analyze the relationship between three confidence measures and economic fluctuations. They find causality from confidence measures to GDP and that these three measures play crucial roles in economic fluctuations. Nadenichek (2007) investigates whether expectation can play a role in the creation of economic downturns using Japan's stagnation period of 1990s. Using simulation techniques, he finds that consumer or business confidence indices take a part in explaining the economic fluctuations.

\section{Methodology and empirical findings}

Turkish monthly data are employed for both confidence indices- $\mathrm{GDP}^{3}$ and unemployment rate

\footnotetext{
${ }^{3}$ GDP is used as the percentage change of seasonally adjusted monthly GDP in constant prices. Monthly GDP is obtained from CBRT website changing the frequency from quarterly to monthly.
} 
$(\mathrm{UR})^{4}$ for the period December 2003-September $2009^{5}$. Short descriptions of both confidence indices for Turkey are given below.

\subsection{CNBC-e consumer confidence index}

Telephone-based survey of CNBC-e consumer confidence index has been conducted on a real-time basis but has been announced on a monthly basis since 2002. The methodology has been adopted from the Michigan University index of consumer sentiment. CNBC-e index is compiled of 700 completed surveys and is composed of the five questions ${ }^{6}$ : (1) We would like to learn your current economic situation. Can you compare your (and your family's) current financial situation with last year? (2) What do you think your (and your family's) future financial situation will be in a year? (3) Can you compare your current expectations about Turkish economy with the previous month? (4) What do you think Turkish economy's situation will be in a year? (5) Do you think that the current period is a good time to buy durable consumer goods such as TV, refrigerator and furniture or vehicles or residence?

\subsection{TURKSTAT consumer confidence index}

TURKSTAT has started to announce a monthly consumer confidence index since 2004. The relevant Household Labor Force Survey covers a sample of all individuals at the age of 15 and above having a job in urban and rural areas of Turkey that provides income. About 7000 individuals are selected on the basis of age, income and status in employment groups. The survey is conducted by computer-based and face-to-face interviews with the sample under a rotation system. The consumer confidence index of TURKSTAT is composed of the following five questions ${ }^{7}$ : (1) Compared to the past 6 months, how do you assess your present purchasing power situation? (2) How do you expect your purchasing power situation to change over the next 6 months? (3) How do you expect the general economic situation in Turkey to develop over the next 3 months? (4) How do you expect the job opportunities in Turkey to change over the next 6 months? (5) Do you think now it is the right moment for people to buy durable consumption goods such as refrigerator, TV, furniture, etc.?

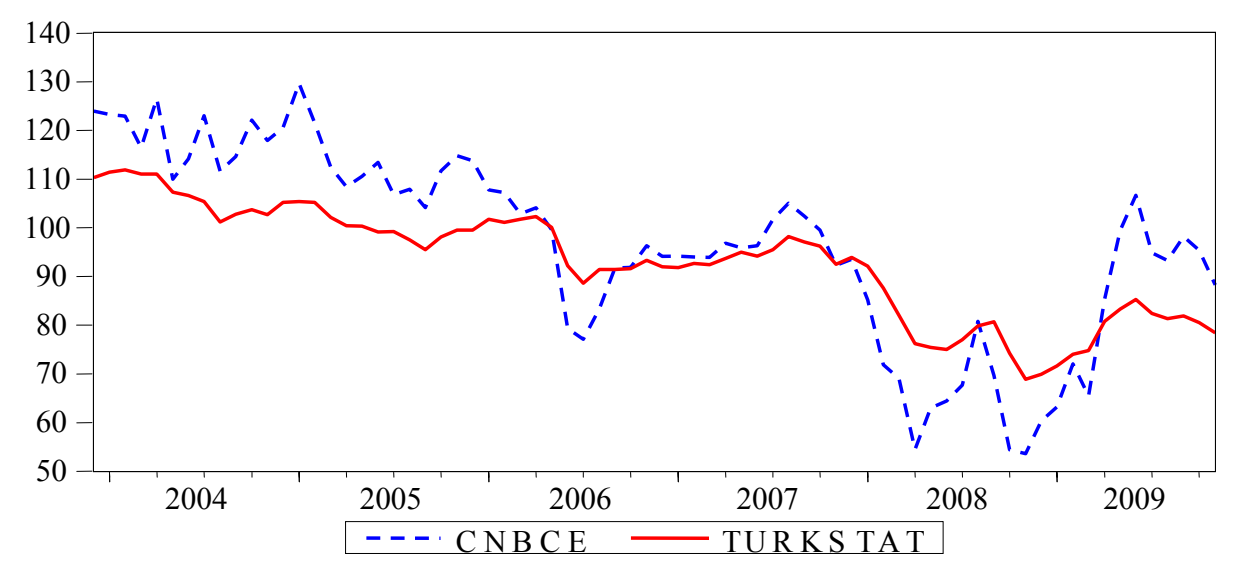

Fig. 1 CNBC-e and TURKSTAT consumer confidence indices

\footnotetext{
${ }^{4}$ The data are obtained from TURKSTAT. Monthly unemployment rate data are interpolated via quadratic match average technique. Afterwards, the data are seasonally adjusted.

5 The data period is specified according to the release date of TURKSTAT.

6 The answer choices for the first four questions are "Better, Worse, Same, No idea", whereas it is "Good time, Bad time, Same" for the last question.

7 The answer choices for the first three questions are "Much more better, A little bit better, Remain the same, A little bit worse, Much more worse, No idea", whereas it is "Increase sharply, Increase slightly, Remain the same, Fall slightly, Fall sharply" for the fourth question, and it is "Yes, it is the right time now, It is neither the right time nor the wrong time, No, it is not the right time now, No idea" for the last question.
} 
Fig. 1 shows the movement of both indices within the given time period. Under the framework of empirical methodology, initially, the correlation coefficient between the indices is reported in Table 1, where $90 \%$ correlation indicates a significant consistency.

Table 1 Correlation between CNBC-e CCI and TURKSTAT CCI

\begin{tabular}{ll}
\hline & CNBC-e \\
\hline TURKSTAT & 0.898 \\
\hline
\end{tabular}

Afterwards, ADF (Dickey \& Fuller, 1979; Dickey \& Fuller, 1981) unit root test is applied, given in Table 2. The test reveals the presence of unit root for each variable as the null hypothesis of unit root is failed to reject in levels and is rejected in first differences.

Table 2 Unit root tests: ADF

\begin{tabular}{|c|c|c|c|c|}
\hline & \multicolumn{2}{|c|}{ In levels } & \multicolumn{2}{|c|}{ In first differences } \\
\hline & Constant & Constant \& Trend & Constant & Constant \& Trend \\
\hline CNBC-e & $-1.916(0.323)$ & $-2.288(0.434)$ & $-7.727(0.000)$ & $-7.691(0.000)$ \\
\hline TURKSTAT & $-1.589(0.482)$ & $-3.392(0.061)$ & $-5.470(0.000)$ & $-5.433(0.001)$ \\
\hline GDP & $-2.338(0.163)$ & $-1.464(0.833)$ & $-9.091(0.000)$ & $-9.488(0.000)$ \\
\hline UR & $-0.791(0.815)$ & $-1.383(0.858)$ & $-4.238(0.001)$ & $-5.132(0.000)$ \\
\hline
\end{tabular}

Notes: Optimal endogenous lags are selected using Akaike information criteria. Max lag is selected as 10. Values in brackets are the $p$-values.

As the variables are observed to be integrated of order 1, cointegration analysis can be applied. Johansen (1988) maximum likelihood cointegration analysis, which allows for the existence of more than one cointegrating vector, is employed. Economic downturn has begun around September 2008. Hence, a dummy variable is included for the crisis period. In Table 3, Johansen cointegration tests with structural break are presented. The cointegration tests reflects that for all four regressions (CNBC-e-GDP, TURKSTAT-GDP, CNBC-e-UR, TURKSTAT-UR), the null hypothesis of no cointegration, i.e., $r=0$, is rejected and the existence of one cointegrating vector is failed to reject. In other words, all regressions imply a long run relationship.

Table 3 Johansen trace test between CCI and GDP, CCI and UR

\begin{tabular}{|c|c|c|c|c|c|c|c|c|c|}
\hline \multicolumn{10}{|c|}{ Regression with GDP } \\
\hline \multicolumn{5}{|c|}{ CNBC-e } & \multicolumn{5}{|c|}{ TURKSTAT } \\
\hline $\mathrm{r}$ & LR & pval & $95 \%$ & $99 \%$ & $\mathrm{r}$ & LR & pval & $95 \%$ & $99 \%$ \\
\hline 0 & 36.50 & 0.001 & 25.06 & 29.83 & 0 & 36.75 & 0.001 & 25.06 & 29.83 \\
\hline 1 & 7.00 & 0.322 & 12.34 & 16.32 & 1 & 7.12 & 0.311 & 12.34 & 16.32 \\
\hline \multicolumn{10}{|c|}{ Regression with UR } \\
\hline \multicolumn{5}{|c|}{ CNBC-e } & \multicolumn{5}{|c|}{ TURKSTAT } \\
\hline $\mathrm{r}$ & LR & pval & $95 \%$ & $99 \%$ & $\mathrm{r}$ & LR & pval & $95 \%$ & $99 \%$ \\
\hline 0 & 24.89 & 0.053 & 25.06 & 29.83 & 0 & 27.87 & 0.020 & 25.06 & 29.83 \\
\hline 1 & 2.47 & 0.887 & 12.34 & 16.32 & 1 & 2.87 & 0.841 & 12.34 & 16.32 \\
\hline
\end{tabular}

Notes: Optimal endogenous lags are selected using Akaike information criteria. Max lag is selected as 10 and constant case is employed. $r$ is the number of cointegrating vector. $L R$ is the Likelihood Ratio statistics and the critical values for $95 \%$ and $99 \%$ significance levels are given. pval is the abbreviation for $p$-value. 
Public and private measures of consumer confidence in Turkey: Substitutes or complements

Table 4 Normalized cointegrating coefficients

\begin{tabular}{llll}
\hline Cointegration equation (1) & Cointegration equation (2) & Cointegration equation (3) & Cointegration equation (4) \\
\hline DV: CNBC-e & DV: TURKSTAT & DV: CNBC-e & DV: TURKSTAT \\
GDP: 0.281 & GDP: 0.283 & UR: -0.255 & UR: -0.175 \\
$(0.004)$ & $(0.002)$ & $(0.034)$ & $(0.035)$ \\
\hline
\end{tabular}

Notes: $D V$ refers to dependent variable. The numbers in brackets refer to the standard errors.

Table 5 Vector error correction estimates for CNBC-e-TURKSTAT and GDP

\begin{tabular}{|c|c|c|c|c|c|}
\hline \multicolumn{6}{|l|}{ Regression with GDP } \\
\hline Lagged endogenous term & $\Delta(\mathrm{CNBC}-\mathrm{e})$ & $\Delta(\mathrm{GDP})$ & Lagged endogenous term & $\Delta($ TURKSTAT $)$ & $\Delta(\mathrm{GDP})$ \\
\hline \multirow[t]{2}{*}{$\Delta(\mathrm{CNBC}-\mathrm{e}(\mathrm{t}-1))$} & 0.171 & 0.01 & $\Delta($ TURKSTAT $(\mathrm{t}-1))$ & 0.474 & 0.129 \\
\hline & {$[1.527]$} & {$[0.411]$} & & [4.757] & [1.768] \\
\hline \multirow[t]{2}{*}{$\Delta(\mathrm{GDP}(\mathrm{t}-1))$} & 1.053 & -0.251 & $\Delta(\mathrm{GDP}(\mathrm{t}-1))$ & 0.219 & -0.257 \\
\hline & [1.784] & {$[-2.015]$} & & {$[1.256]$} & {$[-2.015]$} \\
\hline \multirow[t]{2}{*}{ ec1(t-1) } & -0.298 & 0.032 & ec1(t-1) & -0.244 & 0.05 \\
\hline & {$[-4.257]$} & [2.183] & & {$[-4.907]$} & [1.384] \\
\hline \multicolumn{6}{|l|}{ Regression with UR } \\
\hline Lagged endogenous term & $\Delta(\mathrm{CNBC}-\mathrm{e})$ & $\Delta(\mathrm{UR})$ & Lagged endogenous term & $\Delta($ TURKSTAT $)$ & $\Delta(\mathrm{UR})$ \\
\hline \multirow[t]{2}{*}{$\Delta(\mathrm{CNBC}-\mathrm{e}(\mathrm{t}-1))$} & 0.114 & -0.452 & $\Delta($ TURKSTAT $(\mathrm{t}-1))$ & 0.315 & -1.047 \\
\hline & [1.109] & {$[-2.554]$} & & {$[2.800]$} & {$[-1.683]$} \\
\hline \multirow[t]{2}{*}{$\Delta(\mathrm{UR}(\mathrm{t}-1))$} & 0.045 & 0.745 & $\Delta(\mathrm{UR}(\mathrm{t}-1))$ & 0.032 & 0.575 \\
\hline & {$[0.827]$} & {$[7.985]$} & & {$[1.800]$} & [5.748] \\
\hline \multirow[t]{2}{*}{$\Delta(\mathrm{CNBC}-\mathrm{e}(\mathrm{t}-2))$} & 0.042 & -0.538 & $\Delta($ TURKSTAT $(\mathrm{t}-2)$ & -0.114 & -0.788 \\
\hline & {$[0.417]$} & {$[-3.111]$} & & {$[-0.989]$} & {$[-1.233]$} \\
\hline \multirow[t]{2}{*}{$\Delta(\mathrm{UR}(\mathrm{t}-2))$} & 0.047 & -0.14 & $\Delta(\mathrm{UR}(\mathrm{t}-2))$ & 0.007 & -0.123 \\
\hline & {$[0.983]$} & {$[-1.687]$} & & {$[0.469]$} & {$[-1.387]$} \\
\hline \multirow[t]{2}{*}{$\Delta(\mathrm{CNBC}-\mathrm{e}(\mathrm{t}-3))$} & 0.063 & -0.134 & $\Delta($ TURKSTAT(t-3)) & -0.03 & -1.211 \\
\hline & {$[0.606]$} & {$[-0.745]$} & & {$[-0.258]$} & {$[-1.873]$} \\
\hline \multirow[t]{2}{*}{$\Delta(\mathrm{UR}(\mathrm{t}-3))$} & -0.013 & -0.141 & $\Delta(\mathrm{UR}(\mathrm{t}-3))$ & 0.008 & -0.132 \\
\hline & {$[-0.318]$} & {$[-1.916]$} & & [0.569] & {$[-1.770]$} \\
\hline \multirow[t]{2}{*}{$\Delta(\mathrm{CNBC}-\mathrm{e}(\mathrm{t}-4))$} & 0.094 & -0.412 & $\Delta($ TURKSTAT $(\mathrm{t}-4))$ & 0.048 & -0.598 \\
\hline & {$[0.855]$} & {$[-2.176]$} & & {$[0.402]$} & {$[-0.912]$} \\
\hline \multirow[t]{2}{*}{$\Delta(\mathrm{UR}(\mathrm{t}-4))$} & 0.041 & 0.195 & $\Delta(\mathrm{UR}(\mathrm{t}-4))$ & 0.029 & 0.196 \\
\hline & [0.994] & {$[2.722]$} & & [2.179] & [2.627] \\
\hline \multirow[t]{2}{*}{$\Delta(\mathrm{CNBC}-\mathrm{e}(\mathrm{t}-5))$} & 0.091 & -0.955 & $\Delta($ TURKSTAT $(\mathrm{t}-5))$ & -0.05 & -1.876 \\
\hline & {$[0.955]$} & {$[-5.820]$} & & {$[-0.477]$} & {$[-3.207]$} \\
\hline \multirow[t]{2}{*}{$\Delta(\mathrm{UR}(\mathrm{t}-5))$} & 0.044 & 0.008 & $\Delta(\mathrm{UR}(\mathrm{t}-5))$ & 0.001 & 0.066 \\
\hline & {$[0.988]$} & {$[0.108]$} & & {$[0.077]$} & [0.791] \\
\hline \multirow[t]{2}{*}{$e c 1(t-1)$} & -0.372 & 0.351 & ec1(t-1) & -0.112 & 0.514 \\
\hline & {$[-5.492]$} & {$[3.010]$} & & {$[-4.083]$} & [3.393] \\
\hline
\end{tabular}

Notes: Constant case is employed. The values in brackets are the $t$-statistics. Lag lengths are selected based on AIC. Dummy variable is also included in the regressions.

Also, the normalized coefficients are estimated in Table 4. The results show that one percent increase in growth increases CNBC-e and TURKSTAT indices by $28 \%$ approximately. The impact of GDP is observed to be quite similar in both regressions. The positive and significant coefficients are also consistent with the relevant literature. In the cointegration equation (3) and equation (4), UR displays significant and negative impact on both consumer confidence indices, as expected. It is observed that a one percent increase in unemployment rate 
decreases CNBC-e index by $25.5 \%$ whereas it is $17.5 \%$ for TURKSTAT index. In other words, the impact of unemployment rate is relatively stronger for CNBC-e regression. Even if the indices are examined to be quite close to each other, there is a slight difference from the perspective of the unemployment rate. This can be attributed to the inclusion of expectations on job opportunities within the survey questions of TURKSTAT indices. Hence, the impact of unemployment rate is lower in TURKSTAT compared to CNBC-e index.

Next, a typical vector error correction model (VECM) procedure is employed in order to examine short run adjustments to long run equilibrium:

$$
\begin{aligned}
& \Delta y_{t}=\alpha_{1}+\sum_{i=1}^{m} \beta_{1 i} \Delta y_{t-i}+\sum_{i=1}^{m} \gamma_{1 i} \Delta x_{t-i}+\lambda_{1} E C T_{t-1}+\varepsilon_{1 t} \\
& \Delta x_{t}=\alpha_{2}+\sum_{i=1}^{n} \beta_{2 i} \Delta y_{t-i}+\sum_{i=1}^{n} \gamma_{2 i} \Delta x_{t-i}+\lambda_{2} E C T_{t-1}+\varepsilon_{2 t}
\end{aligned}
$$

where $\Delta$ denotes the first-difference operator; $E C T$ stands for the error correction term; and the terms $\mathrm{m}$ and $\mathrm{n}$ are the lag lengths determined according to the Akaike Information Criteria. The coefficients of $E C T_{t-1}, \lambda_{1}$ and $\lambda_{2}$ depict the speed of adjustments of $\Delta y_{t}$ and $\Delta x_{t}$ towards long-run equilibrium. Table 5 reports the VECM test results. Error correction terms in the regressions, where confidence indices are employed as endogenous variable, are significant and negative. Thereby, the existence of a long-run relationship between the variables is cross-checked by the speed of adjustment coefficient.

\section{Conclusion}

This study analyzes the degree of correlation between the two consumer confidence indices in Turkey, and investigates the extent of the relationship between the indices and some macroeconomic variables, namely as GDP figures and unemployment rate in Turkey. In the first step, the correlation is observed to be very high which signals a consistency among the indices. In the second step, the empirical results have shown the expected long-run relationship betwen GDP, unemployment and consumer confidence, given the period 2003-2009. While GDP figures are observed to be positively affecting consumer confidence, unemployment rate has a negative impact on consumer confidence in Turkey.

Besides, it is crucial to explain the strengths and the weaknesses of the two indices. The strength of the CNBC-e is that it is more compact and is released earlier than TURKSTAT. Moreover, the form of questions of CNBC-e allows it to detect the current structure of the economy better than the other index. Question 3 in CNBC-e contains comparison between current month and the previous, whereas there is no such comparison in TURKSTAT. The alternative question of 3 in TURKSTAT focuses more on expectations. On the other hand, TURKSTAT has more answer choices to be asked within the poll and comprises a higher number of samples. Detailed questions of this index provide an opportunity for researchers and market players to observe some sectoral trends and macroeconomic structure in detail. For instance, TURKSTAT provides an answer about the tendency of consumers to buy cars or houses in the next six months. The index also gives an idea about the availability of job opportunities across the country for the relevant period. However, the weakness of this index is that it is released almost a month later than the preliminary release of CNBC-e.

Consequently, referring to the high correlation, both CNBC-e and TURKSTAT indices are substitute to each other. Nevertheless, the strengths and the weaknesses of both indices render them complementary to each other as well. 


\section{References:}

Acemoglu, D. \& Scott, A.. (1994). Consumer confidence and rational expectations: Are agents' beliefs consistent with the theory? Economic Journal, 104, 1-19.

Adams, E. G. \& Green, E. W.. (1965). Explaining and predicting aggregate consumer attitudes. International Economic Review, 6(3), 275-293.

Afshar, T. \& Zomorrodian, R.. (2007). Stock return, consumer confidence, purchasing manager's index and economic fluctuations. Journal of Business \& Economics Research, 5(8), 97-106.

Carroll, C., Fuhrer, J. \& Wilcox, D.. (1994). Does consumer sentiment forecast household spending? If so, why? American Economic Review, 84, 1397-1408.

Çelik, S. \& Aslanoglu, E.. (2006). Determinats of consumer confidence in Turkey. Turkish Economic Association International Conference, Ankara.

Çelik, S. \& Aslanoglu, E.. (2008). The determinants of consumer confidence in an emerging market: The case of Turkey. In: Aktan, Ç. C., Özkıvrak, Ö. \& Apak, S. (Eds.), Economics of money banking and finance, SOBİAT, İzmir, 157-174.

Dickey, D. A. \& Fuller, W. A.. (1979). Distribution of the estimators for autoregressive time series with a unit root. Journal of the American Statistical Association, 74, 427-431.

Dickey, D. A. \& Fuller, W. A.. (1981). Likelihood ratio tests for autoregressive time series with a unit root. Econometrica, 49(4), 1057-1072.

Johansen, S.. (1988). Statistical analysis of cointegration vectors. Journal of Economic Dynamics and Control, 12(1), $231-254$.

Juster, T. \& Wachtel, P.. (1972). Inflation and the consumer. Brookings Papers on Economic Activity, 1, 71-114.

Lovell, M.. (1975). Why was the consumer feeling so bad? Brookings Papers on Economic Activity, 2, 473-479.

Matsusaka, J. G. \& Sbordone, A.. (1995). Consumer confidence and economic fluctuations. Economic Inquiry, 33(2), $296-318$.

Mishkin, F.. (1978). Consumer sentiment and spending on durable goods. Brookings Papers on Economic Activity, 1, 38-48.

Nadenichek, J.. (2007). Consumer confidence and economic stagnation in Japan. Japan and the World Economy, 19, 338-346.

Oest, R. V. \& Frances, P. H.. (2008). Measuring changes in consumer confidence. Journal of Economic Psychology, 29(3), $255-275$.

Throop, A.. (1992). Consumer sentiment: Its causes and effects. Federal Reserve Bank of San Francisco Economic Review, 35-59.

Utaka, A.. (2003). Confidence and the real economy-The Japanese case. Applied Economics, 35, 337-342.

(Edited by Ruby and Chris) 